\title{
Institutional Work in the Birth of a Carbon Accounting Profession
}

\author{
Delphine Gibassier (corresponding author) \\ Professor \\ Audencia Business School \\ 8 Route de la Jonelière, 44312 Nantes, France \\ dgibassier@audencia.com \\ Phone: 0033638822308 \\ Sami El Omari \\ Associate Professor \\ TBS Business School \\ 1 place Alphonse Jourdain \\ 31068 Toulouse cedex 7, France \\ s.elomari@tbs-education.fr \\ Philippe Naccache \\ Associate Professor \\ INSEEC Business School \\ 27, avenue Claude Vellefaux, 75010 PARIS \\ pnaccache@inseec.com
}

Published in Accounting, Auditing and Accountability Journal:

https://www.emerald.com/insight/content/doi/10.1108/AAAJ-12-2014-

1912/full/html 


\begin{abstract}
Purpose: Within the emergent professional field of carbon accounting, we analyze the institutional work that gives birth to a nascent profession in a multi-actor arena. We therefore contribute to enhancing our understanding of the birth of professions - in their very first steps and infancy.

Design/methodology/approach: This study employs a qualitative approach. We collected data from 1999 to 2015 and conducted 15 semi-structured interviews. One of the researchers was active in the field for two years and participated in carbon accounting events in France as a "participant observer".
\end{abstract}

Findings: Our research contributes to an understanding of the dynamic professionalization process in which the different actors mobilize both creative work and sabotage work. We further theorize how nascent professions structure their project around knowledge, identity and boundary work. At the same time, we develop the notion of sabotage work, which is comprised of two sub-categories of institutional work: counter-work and the absence of work.

Originality/value: To our knowledge, this is one of the first attempts to analyze the birth of an environmental accounting profession. We emphasize both creative work and sabotage work in the professionalization project. We conclude on further research that could be performed on environmental accounting professions.

Type: Research paper

Keywords: carbon accounting, institutional work, professionalization project, Bilan Carbone, environmental accounting, sabotage work

\title{
Acknowledgments
}

The authors would like to thank Hélène Le Teno for her help during the participant observation period. We would like to thank all those who agreed to be interviewed in relation to the professionalization project of the carbon accounting profession in France. Interviewees do not necessarily endorse our analysis, which is our own responsibility. The authors gratefully acknowledge the help of Carlos Ramirez, Wafa Khlif and Tanya Fiedler. The authors also acknowledge the many helpful comments from AFC 2015 and IPA 2015 participants, as well as a joint Royal Holloway-Toulouse Business School workshop held in June 2016, and the Ivey Business School's brown bag seminar held in 
October 2016. We are thankful for the reviewers and editors for their continued support in this research project. 


\section{Abbreviations:}

ABC: Association Bilan Carbone (Bilan Carbone association)

ADEME: Agence de l'Environnement et de la Maîtrise de l'Energie (French environment and energy management agency, referred to hereafter as the French environmental protection agency)

AFNOR: Association Française de Normalisation (French national standards organization) APCC: Association des Professionnels en Conseil Carbone (association of carbon consultancy professionals)

GHG: Greenhouse gas (emissions)

IFC: Institut de Formation Carbone (French carbon training institute)

ISO: International Organization for Standardization

LCA: Life Cycle Assessment

OPQIBI: Organisme de Qualification des Prestataires d'Ingénierie (French certification agency for engineering providers)

SME: Small and Medium sized enterprises

WRI: World Resources Institute

WBCSD: World Business Council of Sustainable Development

Note: Bilan Carbone is a trademark first registered in 2011. It refers to the carbon accounting tool and methodology initially developed by the French environmental protection agency, ADEME, and now owned by the ABC (Association Bilan Carbone). This research paper refers to the trademarked tool, therefore the ${ }^{\circledR}$ is taken as read. 


\section{Introduction}

Research on how professions establish themselves as legitimate and build their occupational mandate remains scant (Carnegie and Edwards, 2001; Carter et al., 2015; Fayard et al., 2017; Howard-Grenville et al., 2017). The literature has only rarely considered professions in the early stages of institutionalization, before the main activities become concerned with solidification (Edwards et al., 2007). Professionalization stories usually begin when the occupation is in its adolescence (long after the process has actually begun), and consequently are usually "left-censored" (Nelsen and Barley, 1997). Moreover, professionalization projects are complex and contested in nature, and a central issue within the sociology of professions is to understand the process by which occupations transform themselves into nascent professions (Nelsen and Barley, 1997; Mc Cann et al., 2013). It is important to develop the interactions between the different actors in a professionalization arena, to "take measure of their power, describe their alliances and contests" and document their effect on the professionalization project (Light, 2014, p.325).

In order to fill these gaps, our study answers the following research question: what strategies are deployed and mobilized by the different actors involved in the development of a nascent professional project? To address this question, we undertook a study of the birth of the carbon accounting profession in France, where we focus on the process of professionalization rather than on the outcome. To do so, we draw on the institutional work literature in order to gain a deeper understanding of the purposive actions that aim to develop a new profession (Lawrence and Suddaby, 2006). We adopt a qualitative approach to study the professionalization project of carbon accountants in a French context, which combines interviews, participant observation and secondary data from the field.

The original features of this case, along with the theoretical framework mobilized, contribute to efforts to enrich both the sociology of professions (Muzio et al., 2013; Suddaby and Viale, 2011) and our understanding of social and environmental accounting through the lens of "professionalization" (O'Dwyer et al., 2011; Renaud, 2014) in three ways. Firstly, our research highlights that the early steps of a professionalization project are a highly dynamic process in which actors mobilize two types of work: creative and sabotage. We contribute to the sociology of professions by developing three types of creative work involved in the process through which professions come to be born. Secondly, we contribute to the theorization of two types of sabotage work, refining our understanding of the complex and contested nature of professionalization projects (Nelsen and Barley, 1997). Thirdly, we enrich the expanding literature on environmental accounting professions through this rich empirical study of how carbon accounting professionalization took place in a French context. 
The remainder of the paper is organized as follows. The next section presents a literature review of the birth of professions. We then propose a theorization of the birth of professions through the lens of institutional work. The fourth section presents our research design. The fifth section develops our findings on the birth of the carbon accounting profession. Finally, we discuss our findings before presenting our concluding remarks.

\section{The birth of professions}

The analysis of the early days of professions often involves the adolescence of a profession (Nelsen and Barley, 1997; Fayard et al., 2017), when solidification takes place. These studies, often called "closure studies", focus on "the demarcation of the privileged group" and "securing the sanction of the state for the monopolistic structures proposed" (Walker and Shackleton, 1998). They often focus on the institutional level and the central role of the state in the political process of market closure (Ballas, 1998; De Beelde, 2002; Coronella et al., 2015). This literature does not provide useful insights on the early days of a nascent profession where practitioners may not always be very articulate or intent on constructing the new profession (Nelsen and Barley, 1997). In fact, these early days are difficult to capture in research on established professions.

To capture the birth of the accounting profession in the United Kingdom, Edwards et al.

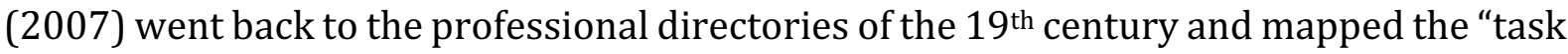
area" specified by the burgeoning accounting professional group to demarcate its jurisdiction. They also note that it was accompanied by increased teaching on the subject, and describe how accountants modified their knowledge base to fulfil new requests, explaining their expanding jurisdiction in the 19th century (Edwards et al., 2007). This helps us to understand how the expertise of the future accounting profession was claimed even before any legal protection was enacted to provide closure around the profession (Edwards et al., 2007; Walker, 2004).

Another professional project was identified through the way service designers claimed differentiated values, enacted through their work practices (Fayard et al., 2017). By distinguishing themselves through values and practices, they were able to carve out their own occupational mandate. Service designers used the word "ethos" to describe what made them different - the spirit of their community that infused their attitudes and aspirations (Fayard et al., 2017). Their ethos was composed of holism, empathy and cocreation and was crucial in differentiating them from traditional designers and other professions such as management consultants (Fayard et al., 2017). Similarly, Nelsen and Barley's work (1997) followed the professional rhetorical claims of emergency medical 
services (EMS) as they turned from proficiency and altruism to medical competence. The new paid-service EMS defined themselves as opposing the values and ethos embodied in the unpaid EMS (Nelsen and Barley, 1997) to attract customers' attention. In the very early stages of the birth of professions, members of a new community define their belonging to a particular group by identifying what makes them similar and by drawing distinctions with those they believe are different, or do not belong to the nascent profession (Van Maanen and Barley, 1984; Fayard et al., 2017).

However, the presence of like-minded individuals with similar work interests and practices does not always immediately lead to a coalition capable of creating a new profession. For example, the 19th century UK accountants who remained unorganized throughout much of the period (Edwards et al., 2007). Further investigation of how a group of like-minded individuals can form a profession is therefore required.

It is necessary to gain a better understanding of this phase of professionalization. Abbott admitted to having "largely ignored the issue of when groups can legitimately be said to have coalesced into professions" (Abbott 1988, p. 315; Fayard et al., 2017). Consequently, we will first contribute to enhancing our understanding of the birth of professions - in their very first steps and infancy. Moreover, the literature on the birth of professions is focused on the would-be-professional group alone. It does not address the dynamic of the early steps of the institutionalization process between the would-be professional group and the other actors present in the professionalization arena. Our study aims to fill these gaps by employing an institutional work lens. We seek to shed light on the process, its complexity and the different strategies of the various actors involved in the creation of a new "carbon accounting profession".

\section{Institutional work and the birth of professions}

Institutional theory is uniquely positioned to analyze and understand the profound changes that professions experience (Cooper and Robson, 2006; Kipping and Kirkpatrick, 2013). One important feature of institutional theory is that it highlights the relationship between professions and broader institutional projects (Muzio et al., 2013; Suddaby et al., 2015). Additionally, Ramirez (2013) and Muzio et al. (2013) argue that professions in modern society have assumed leading roles in the creation and maintenance of institutions. Institutions are understood as being infused with value, and as acting as vehicles of group integrity, producing a distinct identity for the group (Selznick, 1957). They have "distinctive outlooks, habits and commitments" that lend them the particularity of creating social integration (Selznick, 1957, p.40).

To highlight the multiple strategies deployed and mobilized by institutional agents in creating new professions (Lawrence et al., 2009), we analyze the birth of a new 
contemporary environmental accounting profession through the lens of institutional work, switching the focus onto actors and trying to determine what kind of actions affect institutions. As such, we investigate how do actors do strategic purposive actions in order to creating, maintaining and disrupting institutions (Lawrence and Suddaby, 2006).

\section{Creative work in the birth of a profession}

We focus on a profession's creative work, as very little is known about the work devised to carve out a new space for a nascent profession. We draw on the literature on the birth of professions in order to identify three categories of professional work: knowledge work, identity work and boundary work.

\section{Knowledge work}

As a new profession emerges, the first step is to discover colleagueship (Fayard et al., 2017). Colleagueship forms around a commonality found in shared expertise (McMurray, 2011). Hence, the first category of institutional work in nascent professions is therefore knowledge work - i.e. linking practice to formal knowledge (Nelsen and Barley, 1997). Beaverstock et al. (2010) state that the status of new professions depends on their ability to handle "technical, risk-laden business challenges", with this ability forming their "cultural capital". As Nelsen and Barley (1997, p. 620) point out there is "a need for a new profession to construct a reputation for expertise".

The necessary problematization of the new expertise consists in underlining how the knowledge claims offer solutions to the problems that the audience faces (Gendron et al., 2007). First, inscriptions (standards, measures and guidelines) can be developed to support the network of expertise being built and gradually serve as tools to provide confidence to would-be professionals so that they can speak authoritatively about this new expertise (Gendron et al., 2007). A second technique is to link the claims to claims whose legitimacy is better established (Etzion and Ferraro, 2010). Moreover, new professions can enrol audiences by translating this new knowledge into financial claims, such as potential sales increases (Gendron and Barrett, 2004). New knowledge claims can also be supported if they are adopted by other similar jurisdictions globally (Gendron et al., 2007).

Recent professionalization projects have switched from formalized knowledge bases defined through training courses and examinations, to more complex, symbolic expertise (Beaverstock et al., 2010). Eyal (2013) analyzes expertise "in the making" as a network of objects, actors, techniques, devices and institutional and spatial arrangements. The network is in motion and continuously reflects the efforts of proponents of the new 
expertise to develop knowledge claims that are suitable and fit the interests of the targeted audience (Gendron and Barrett, 2004).

\section{Identity work}

New professions need to develop a cultural footing to be able to claim that their skills warrant special status (Nelsen and Barley, 1997). The second category of creative work to build up a new profession can therefore be gathered under the banner of identity work. Lawrence and Suddaby (2006) define it as the creation of a relationship between an actor and the field in which the actor operates. Identity work has been said to be one of the most important institutional work streams in the construction of a new profession (Creed et al., 2010). Forging a profession's identity involves developing a mutual understanding of values, beliefs and ways of thinking that is internally shared and externally recognized, providing the cultural underpinnings necessary for the new profession's legitimacy (Fayard et al., 2017). Identity work is composed of both the definition of the identity of the new profession and advocacy that supports identity claims.

The identity of a new profession is often based on shared competencies (Edwards et al., 2007; Evetts, 2011) and a strong work culture - such as defined professional performance measures (Oakes et al., 1998). Secondly, identity work can also be based on common values and beliefs (Fayard et al., 2017), like the recyclers' identity that "was connected to the ideals of the broader environmental movement" (Lounsbury, 2001, p. 33). Identity can then be expressed through "materials" such as names (naming work), narratives, symbols or rituals (Rao et al., 2003).

One of the most important steps in constructing identity is to mobilize support and construct legitimate accounts (Creed et al., 2002). Advocacy is defined as "the mobilization of political and regulatory support through direct and deliberate techniques of social suasion" (Lawrence and Suddaby, 2006). In the case of a burgeoning profession, advocacy is a key element that actors can use to acquire the legitimacy they need to affect the creation of the new profession (Lawrence and Suddaby, 2006). It is linked to the creation of an identity for the profession as it legitimates "who they are" in what they are doing. The recognition of these new professionals as a legitimate group capable of mobilizing political and regulatory support confirms the identity created and defined within the groups of new professionals.

Finally, identity work often leads to, or is closely linked with, boundary work, as boundaries sharpen a group's identity in the minds of its members (Cross et al., 2000). Forming an association can serve as the basis for creating a group identity (Ramirez, 2001; Lounsbury, 2001). A professional association can provide individuals with "institutional landmarks, classifications, principles of identification to think [about] the 
world and to think themselves" (Ramirez, 2001, p. 415). A professional association can also serve as the foundation for legitimizing the new profession, bringing collegial authority, mutual support and cooperation (Evetts, 2011). This sense of solidarity and identity then gives the new profession the moral authority to claim that its work and opinions are appropriate and relevant (McMurray, 2011).

\section{Boundary work}

The third category of "creative work" can be gathered under the banner of "boundary work". Suddaby et al. (2015, p.54) define it as "the process by which actors, typically professional associations, construct occupational closure or socially legitimated claims to exclusive expertise". Organizing boundaries can be considered as the solidification and legitimization efforts of the nascent profession (Bucher, 1988), and the form that the "closure" takes is inflected by the political context within which it is obtained (Larson, 1990).

We identified two forms of boundary work. The first classically consists in complete closure with "strong" boundaries, such as creating an association linked to licensing and admission procedures, as well as overseeing discipline and having a sanctioning system in the event of professional incompetence (Richardson, 1997; Walker, 1991; Walker and Shackleton, 1995; Ramirez, 2001). Secondly, would-be professions can create barriers around knowledge by demanding examinations and tests (Sian, 2006). This can take the form of specialized university programs that attempt to make the right to use the title of a profession dependent on certain qualifications (Groß and Kieser, 2006). Organizing an accreditation and/or certification process limits access to job opportunities (Malhotra and Morris, 2009). Finally, would-be professions can also install barriers through state legislation and create monopolies (Walker and Shackleton, 1995, 1998). By seeking "strong" boundaries, would-be professions seek protection for their professional group and attempt to control its position (Bucher, 1988).

The second type of boundary work is based on "soft" boundaries. In this case, an association allows controlled membership, with the aim of controlling the identity of the professionals within it. The association serves as a basis for framing an expertise as legitimate when trying to expand jurisdiction beyond traditional activities (Lawrence, 2004). The goal of associations in nascent professions using soft boundary work is often to separate their membership from the "unworthy" and therefore protect both knowledge work (Kipping and Kirkpatrick, 2013) and identity work (Walker, 1988).

\section{Sabotage work}


A recent move in institutional work research has been to explore the purposive actions that make it difficult to achieve one's objective. In this perspective, we emphasize how this kind of work sometimes even leads to failure, and results in unintended consequences (Hampel et al., 2017). In his seminal work, Abbott (1988) acknowledged the complex and multi-directional paths that professional projects take in early stages. Professionalization projects are often characterized by power imbalances between different players, ending up in complex and contested combinations of work (McCann et al., 2013). Although institutional work stories often only account for the creative work that takes place in allowing institutions to emerge (such as building networks, advocacy, constructing, theorizing...), it is necessary to better account for the countervailing powers (Light, 1995, 2014). Neglecting the complexity of emergence processes would create only partial accounts of nascent professionalization projects (Lawrence et al., 2011; McCann et al., 2013).

\section{Counter-work}

Nascent professions often also face the daunting task of carving a space for themselves in a crowded professional arena and competitive professions will play a different score by trying to counter the progression of a new project (Carnegie and Edwards, 2001). Counter-work is therefore the work being conducted by actors in the professional field to undermine the birth of the new profession while the creative work is also underway. McCann et al. (2013), for example, acknowledge that "other" powerful organizations in the medical profession field had imagined their own directions for the paramedics profession, which were not always in line with, or even contradicted, the College of Paramedics' aims. The professionalization of medicine is also acknowledged to be complex and problematic, and highly dependent on "wider political negotiations" (McMurray, 2011). The Belgian "experts-comptables" (chartered accountants) reacted to the creation of the auditor profession by creating a "National Commission to Study the Status of the Accountant" to increase "their impact on political decisions about the structure of the auditing profession", and to favour their solution, which was a common association between auditors and experts-comptables, and not the birth of a competing profession (De Beelde, 2002, p.455). In 1968, the French "experts-comptables" tried to stop the creation of the "commissaires aux comptes" (auditors) association (El Omari et al., 2013).

\section{Absence of work}

New professions are often described in terms of the "absence" or "weakness" of the traits associated with traditional professions (Groß and Kieser, 2006; Kipping and Kirkpatrick, 2013). For example, French accounting professionals created a high-level diploma in 1928. They thought that the state would react in the same way as it had done with other 
prestigious professions (medicine and lawyers). However, the State remained insensitive to this action and did not work to consolidate the professionalization of accountants during this period (Ramirez, 2001). A second example is the paramedic profession (McCann et al.,2013), which did not obtain the same protections that other established professions such as law and medicine had obtained in their earlier professionalization projects. The authors note that the absence of such protections could be a consequence of the counter-work observed and the power imbalances that affected the work of the different actors in this professionalization project. Finally, the state's lack of intervention in Morocco to reconcile the position of the historical professional associations left sufficient time for the associations opposed to the reform to organize themselves (El Omari and Khlif, 2014).

However, absence "is in fact actively produced as [something] non-existent, that is - as a non-credible alternative to what exists" (de Sousa Santos, 2006, p.15). Practitioners generally develop their strategy to provoke a response or an action on the part of stakeholders and gain their support (Nelsen and Barley, 1997). This expectation is based on the knowledge that professionals have of other professionalization processes, what "makes it possible" (Giovannoni and Quattrone, 2017). In the case of boundary or identity work, the absence of an expected reaction could thwart the plans of professionals, or at least hinder them. In other words, absence produces organizing effects on the professionalization project (Giovannoni and Quattrone, 2017). In a nutshell, absence is a purposive action that aims to produce an expected effect even if the actor who used it is not necessarily cognizant of the potential consequences of its strategy (Leca and Naccache, 2006; Hayne and Free, 2014). These purposive actions are "present absences" (Giovannoni and Quattrone, 2017; Sousa Santos, 2006), that trigger dynamisms "because of the gaps that they persistently entail" (Giovannoni and Quattrone, 2017, p.2).

By using institutional work as a sensitizing theoretical framework for analyzing our empirical case of the birth of an environmental accounting profession, we seek to answer the following research question: what strategies are deployed and mobilized by the different actors involved in the development of a nascent professional project?

\section{Research Design}

The aim of this research is to explore the birth of a new profession in the domain of environmental accounting, which is rarely empirically possible, and in a relatively unexplored setting when it comes to the sociology of professions. This research is a longitudinal case study from 1999 to 2015 . We have chosen institutional theory to explore both the contextual conditions (the French cultural arena and the topic of carbon) and the actions taken, i.e. the work and process of creating a new profession (Kipping and Kirkpatrick, 2013). To this end, our paper combines institutional work with the literature 
on the sociology of professions. Making institutional work visible requires rich, detailed case studies (Lawrence et al., 2009). The institutional work perspective also "attends more closely to practice and process than to outcome" (Lawrence et al., 2011). We therefore collected data through participant observation and semi-structured interviews. Secondary data were collected from the archives of the French environmental protection agency and press articles among others. This combination of qualitative methods makes our analysis more robust (Kipping and Kirkpatrick, 2013) and has allowed us to depict the emerging professional field in detail, as well as the actors and the work they performed while trying to create this nascent profession.

\section{Data collection}

One of the researchers was active in the field for two years and participated in carbon accounting events in France as a participant observer. From 2010 to 2012, the researcher was a carbon accountant in a French multinational. The researcher thus participated in the private meetings of several CAC 40 groups on carbon strategy organized by a major French carbon consultancy, and attended two major events in 2010 and 2012 organized by the same consultancy. Through insider conversations with carbon accountants and consultants from 2010 to 2015, the researcher built up a good understanding of how the new profession was being shaped. In June 2013, the researcher also participated in a conference organized by the French environmental protection agency to present the French GHG (Greenhouse gases) emissions database, in a carbon conference in October 2013 also organized by the agency, and in a technical day led by the APCC (Association des Professionnels en Conseil Carbone) in November 2013.

We conducted 15 semi-structured interviews over a period of three years from early 2012 to late 2015. This allowed us to highlight different periods and events in the professionalization project, as well as to gather impressions and feedback from interviewees over a three-year period. All interviews were recorded and transcribed. Interviews lasted from about 22 to 80 minutes, with an average of 53 minutes. Six interviews were conducted face to face and nine by phone, totalling 800 minutes. All interviewees gave their permission for the interview to be recorded. All asked to remain anonymous. Participants in the interviews were members of the French environmental protection agency's team on climate change (former and current), carbon consultancy professionals, some of whom were active in the professionalization process and others who were more passive, and one client who tested the initial Bilan Carbone tool in 2003. The questions addressed to the professionals related to themselves (their background), their organization, how they worked before and after the concretization of the association, their role in the association, the development of the nascent profession and

its future. We also continued to have informal conversations about the professionalization 
project from 2015 to 2019 with two members of the APCC, allowing us to strengthen our analysis and present our work to them for discussion.

Secondary data related to the tool were gathered through the media and through access to the archives of the French environmental protection agency. We also gained access to a forum for discussions between professionals. Although we were not allowed to use its content as direct quotations, it gave us greater insider knowledge on the creation of the professional association. Newsletters of the ABC (Association Bilan Carbone), APCC and the French environmental protection agency were gathered and analyzed, as were all publicly available documents on the APCC. In all, 110 secondary documents were collected on the carbon accounting field from 1999 to 2015.

\section{Data analysis}

Each interview recording was fully and accurately transcribed. Data were coded using a data analysis software program (Atlas.ti), which allows manual line-by-line coding of text data. The coding process was performed in two stages: the first stage addressed categories that had emerged from the field and the structure of our questionnaire. Themes such as "quality credentials", "licensing", "naming the profession", and "training" were coded at this stage, as were the different actors (the French environmental protection agency ADEME, APCC, ABC, the accounting profession, etc.) and finally the institutional context. Secondly, the first codes were reorganized into theoretical categories driven by the theory of institutional work (knowledge work, identity work and soft boundary work), and grouped under the aggregate theoretical dimension "creative work". Finally, the counter-work and absence of work were the last to be coded as stakeholders' efforts to undermine creative work, and grouped under the aggregate theoretical dimension "sabotage work". In total, 395 excerpts of interviews were coded.

\section{INSERT FIGURE 1 ABOUT HERE}

\section{Findings}

Based on our institutional framework we explore the nascent profession of carbon accounting in France (figure 2). First, we will develop the three types of institutional work that can be grouped under the banner of creative work. Then we will demonstrate how counter-work and absence of work played a role in fragilizing the professionalization project (without sabotaging completely the burgeoning profession).

INSERT FIGURE 2 ABOUT HERE

\section{Knowledge work}




\section{The institutional environment on climate change, conducive to creating new knowledge}

As part of the creative work of this nascent profession, we need to introduce the institutional field of climate change over the last 20 years in order to pinpoint some of the broader dynamics that have affected the development of this would-be profession (De Beelde, 2002; Hodgson et al., 2015), and notably its knowledge work. The turning point that led to an era of "carbonomics" was the signing of the Kyoto Protocol in 1997. It was the first binding agreement under which states had to reduce their emissions of greenhouse gases, with targets and timetables. It was the trigger for the development of new economic tools to help reduce GHG emissions, such as emissions trading schemes, and thereby corporate carbon accounting standards soon became a necessity.

In the United States, a working group composed, including the World Resources Institute (WRI), started to work on a corporate standard for carbon accounting in 1998. The GHG Protocol entity was created jointly by the WRI and the World Business Council for Sustainable Development (WBCSD) in late 1997. In 1998, the WRI and WBCSD convened a core steering group comprised of members from environmental groups and from industry to guide the multi-stakeholder standards development process (GHG Protocol Website). In 2001, the first carbon "Corporate Accounting and Reporting Standard" was published.

\section{INSERT TABLE 1 ABOUT HERE}

In France, the Bilan Carbone carbon accounting tool was developed between 1999 and 2003 by the French environmental protection agency and a consultant engineer, tested by a few design offices and organizations in 2003, and launched in 2004. The Bilan Carbone was a huge success in both training and implementation during the period from 2004 to 2010, becoming the name for carbon accounting in France. The Bilan Carbone is defined as: "a method of diagnosis related to greenhouse gas emissions aiming at establishing an inventory of direct and indirect emissions for an activity or a territory from easily accessible data, then to propose on this basis, recommendations for actions to reduce emissions" (ABC, 2015). Following the availability of the tool, and around the promotion of it in France, a strong group of "carbon accountants" emerged.

\section{Creating the first French carbon accounting methodology}

In the late 1990s, an independent consultant became interested in how teleworking could help saving carbon emissions, notably in the area of transport. While attending a conference, he suggested to a French government official that a methodology could be constructed to allow a company's direct emissions to be compared with those generated 
through externalization. He was steered towards the French environmental protection agency (EPA). His experimental project was to investigate a carbon emissions accounting methodology that would transcend organizational legal ownership. At that time, there was no knowledge of the future GHG Protocol Corporate Standard in France, and both methodologies were conceived at the same time on opposite sides of the Atlantic.

The methodology, which was later labelled "Bilan Carbone", was designed to allow a given national economic agent to move from a global emissions threshold to its own impact on carbon emissions. The tool went beyond the mere "counting" of emissions, and was designed to be used as a tool for shaping climate and economic strategies.

Bilan Carbone was conceived as an easily understandable environmental accounting tool, unlike its predecessor in France, the ecobilan (Gibassier, 2017). In a way, the capacity to facilitate a rapid dissemination of carbon accounting and climate change expertise was built into its very identity:

"There are several advantages for us. It's [the Bilan Carbone] educational, because the results can be understood straight away." (User 1)

After the first model of the tool was made available to the French EPA team in 2002, it decided to run an experimental protocol with companies to see what results it would yield. In 2003, a new director arrived at the French environmental protection agency. She realized that the Bilan Carbone could be useful for helping French companies and local authorities to become eco-friendlier. It was therefore officially launched as the carbon accounting tool of the French EPA in early 2004.

\section{Creating the pool of experts}

After the tool's launch, the French EPA fostered the development of a profession based on carbon accounting services provided using Bilan Carbone. The French environmental protection agency began by training the first "carbon accountants" in 2004. They were often from design offices [1] (Bureau d'études) with expertise in energy- or environmentrelated fields, as no one had yet positioned themselves in the area of climate change, let alone carbon accounting. Between 2004 and 2007, around 100 people were trained per year.

They then massified the training by copyrighting the tool and designing two-day training courses. Another two days were quickly added, as climate change knowledge remained scarce. It was necessary to raise awareness about climate change and explain the principles behind the tool and the different steps so that people were operational after the training course. In 2008, the number of trainees rose to 800 and later reached 1,500 
people per year. The more people it trained, the more the state agency thought its teams were achieving their goal of knowledge dissemination:

"They came out of the training course fully convinced that we absolutely had to go through that stage, it was the tool we needed. Afterwards, they were the ones who convinced the others. It had a snowball effect." (French EPA 3)

\section{INSERT TABLE 2 ABOUT HERE}

The agency also implemented a licensing system. Training course participants received a licence that allowed them to use the Bilan Carbone according to the rules explained in the licence. The dissemination model aimed to reach a maximum number of people by offering an all-inclusive, easy-to-use tool requiring only limited initial company data and for which training was provided. The aim was to make the expertise available to all kinds of corporations, including SMEs (French EPA 2). Unlike the "ecobilan" (Gibassier, 2017), the tool had been designed to be easily understandable and easily applicable even when only limited data were readily available in organizations, fostering its easy and rapid dissemination among and through design offices and organizations.

\section{Accelerating diffusion}

After it had financed the tool's creation, moulded its identity into a very easy-to-use carbon accounting tool, and trained carbon consultants, the French environmental protection agency (EPA) put together a financial aid scheme to finance up to fifty percent of the cost of drawing up a Bilan Carbone with a licensed design office. Additionally, from 2004 to 2010, the Bilan Carbone was distributed by the regional French environmental protection agency's delegations, which fostered its diffusion locally. Moreover, the EPA fostered the use of carbon accounting in applications for public tenders.

A carbon accounting market was created from scratch through the funding system and the training of carbon accounting experts. By 2011, a total of more than 3,700 Bilan Carbones had been performed. Organizations working on climate change were doing so voluntarily, and the state agency backed the would-be professionals in their efforts to develop the market around the Bilan Carbone because it was synchronized with the national policy on climate change:

"We had the French environmental protection agency's full support. They wanted to use the Bilan Carbone as a sounding board and to spur discussions on climate change." (Consultant 7)

\section{Extending the network of carbon accounting expertise}


In 2010, EPA was made responsible for writing the carbon accounting guidelines that would support the implementation of Article 75 of the Grenelle 2 Law, the large corporations' obligation to report on carbon emissions. The agency therefore had to let go of the Bilan Carbone, as there was a conflict of interest between owning one's own carbon accounting tool and the public carbon accounting rules to be introduced through the law. The Bilan Carbone tool was therefore given to a new association, the "Association Bilan Carbone" (ABC) at the end of 2010, to continue the work performed by the French environmental protection agency from 1999 onwards to diffuse carbon accounting.

The carbon accounting expertise incorporated in the tool through the calculation (excel), the emissions factor database and the methodological guide was scattered into different agencies after 2010. First, the emissions factor database was kept by the French EPA, which managed it as the French database for carbon-related emissions factors. This database thus remained accessible to those wishing to draw up a Bilan Carbone or perform any other carbon accounting (GHG Protocol or a "Bilan GES"). The database, as a key strategic element of carbon accounting, had to remain public (under state supervision). The ABC became the owner of the Bilan Carbone tool: both the methodological guide, which they were tasked with updating (and which they have translated into other languages), and the Excel tool (without the emission factors integrated in the tool). Finally, the training element was incorporated into the Institut de Formation Carbone (IFC), a branch of the newly formed APCC. Carbon accounting expertise was therefore scattered among three different actors of the carbon accounting arena after 2010.

\section{INSERT FIGURE 3 ABOUT HERE}

\section{Recentralizing the carbon accounting discourse around the EPA}

By keeping a key element of carbon accounting (the French GHG emission factors database) the EPA retained its status as the technical guarantor of carbon accounting in France. Witnessing the collapse of the Bilan Carbone market after 2010 [2] (when they had to let go of the Bilan Carbone), the French environmental protection agency made it their responsibility to become carbon accounting's voice once again. The climate change team within the agency started to redevelop technical topics around carbon accounting. The agency-initiated industry guides on carbon accounting, thus continuously developing carbon accounting specificities and technicalities. This allowed the French EPA to take back on board the discourse around carbon accounting.

The EPA, the APCC and the ABC started to share a structured and coherent discourse on carbon and energy topics. The EPA and the APCC shared their diagnosis of the need to 
redevelop the carbon topic in France and in 2014 developed regional forums on carbon. Each of these events brought together more than 100 people around the carbon topic.

\section{Identity work}

The second type of creative work that we identified is "identity work". From 2004 to 2010, expertise in carbon accounting was created and diffused via the EPA. Both the tool and the training courses made it possible for consultancies to gain expertise and build a business to diffuse this carbon accounting expertise within organizations. In 2010, when management of the Bilan Carbone was given to ABC, the EPA also explicitly asked the consultants to organize themselves as a professional group within an association (the APCC) - to become the voice of carbon accounting in the climate change debate in France.

\section{Who is in, who is out?}

The group of consultants were united by the fact they were performing the same task (carbon accounting), using the same tool (Bilan Carbone). Moreover, they had all been trained in the same two two-day training courses at the French environmental protection agency. Therefore, EPA had clearly built a professional community with a well-identified expertise, that united into the APCC (Consultant 2).

On the association's inception, the APCC members initiated a reflection process to determine who they actually were. The definition they came up with was vast, although focused on GHG emissions, and did not mention the word "accounting". "A professional in carbon consulting is a consultant working with any type of organization to drive missions, studies and elaborate strategies relative to GHG emissions" (APCC Code of Conduct). In fact, as reformulated by an interviewee, the mission of a carbon professional included expertise, consulting, training, raising awareness and organizing events focusing on reducing GHG emissions for any type of organization. Their first difficulty was to agree on a list of tasks, which ended up being quite long. They did however manage to exclude one type of climate change work, namely creating carbon offsets:

"We shouldn't confuse carbon offsets with what we do, for example. Can people offsetting carbon belong to the APCC? We reached the conclusion that offsetting is not part of the APCC, while consultancy can be." (Consultant 1)

Secondly, they agreed on a professional name: the "conseil carbone" (carbon consultant). This name was important, as there were no credentials that distinguished a carbon professional from any other professional, apart from the two times two-day training course. However, despite finding a common name, it was rarely used on business cards, with interviewees preferring simply consultant or manager. This confession from most 
interviewees of this burgeoning profession indicates a weak identification with the chosen name and the definition given to support it.

The debate on their core identity, as well as the definition of a "carbon consultant" (conseil carbone) continued over the years. Should they enlarge the portfolio of activities to include Corporate Social Responsibility activities or multi-criteria analysis and product accounting? Would it mean dilution or salvation? Some continued to assert that the specialized technical knowledge necessary to be a professional carbon consultant was the basis of their identity. Indeed, "carbon is still very specialized. You need a technical level for the carbon and energy parts that not everyone has. We have to remain specialized in this area.. When you start talking about energy, greenhouse gas emissions, power sources or reduction plans it's technical. Personally, I'd prefer the carbon profession to stay specialized. It seems more appropriate in light of the subject." (Consultant 6)

\section{Shifting from accounting to climate change consultants}

Gradually, the profession's members started to shift from being carbon accountants, centred on the Bilan Carbone tool, to being climate change "consultants", as per their decision on their profession's "name" was indicating. Claiming they were following a market change, they drove the carbon professional from accounting to consulting. They claimed that clients themselves were no longer interested in accounting but instead in the action plans to reduce GHG emissions that consultants developed on the basis of accounting results. Gradually, contempt for carbon accounting-only customer engagements arose within the profession. They gradually turned to providing strategic advice on climate change strategies: "If it's only carbon accounting, we might give companies the impression that what matters is just handing in a report at the end of the year. If we do that, the problem is that we'll talk a lot about carbon, but we'll never reduce emissions." (Consultant 4).

\section{Advocacy to underpin identity formation and recognition}

Uniting into a group of professionals under the banner of the APCC allowed members to start representing their voice in the climate change field, as a consultant interviewed emphasized. The APCC wished to represent the profession's interests within general public debates on climate change, within the national coordination centre on carbon reporting, and at the ministry and the EPA. Indeed, the climate change debate was trusted by large companies, who were not so keen, for example, to have the scope 3 accounting imposed in the law (a more stringent view on accounting, reporting and consequently, reducing emissions). On the other hand, the APCC was composed of consultants with a certain idea of how climate change should be conducted and strategized within 
organizations, with a strong focus on emissions reduction, within the limits decided by the IPCC:

"In my opinion, the APCC's best defence is the recognition of its very real expertise and the way it drives the profession. Therefore, it's also the identity of a contributing player." (Consultant 2)

\section{Soft boundary work: becoming carbon accounting "professionals" Creating a professional association}

The distribution of the Bilan Carbone tool set the stage for a first group of practitioners, including the initial trainers from 2004 and a larger group of design offices that developed around the tool and their capacity to "sell" the first counting of carbon emissions, from 2004 to 2010. A first step in formalizing these new "carbon accountants" was taken through a "users' club", where trained consultants could discuss technical topics, including emission factors and the peculiarities of certain industries. Although informal groups of trainers and consultancy "users" existed, no formal organization of the profession was driven by the French environmental protection agency until 2010. As the EPA accelerated its programme of training people on the Bilan Carbone tool, it started to raise the issue of the need for a "professionalization" process for the nascent group of "carbon accountants":

"The French environmental protection agency told us it would be good to get organized and be more professional so as to have official discussions on the follow-on to the Bilan Carbone, the future etc." (Consultant 1)

The founding general assembly gathered 80 people. The founding members wanted to structure the profession, professionalize the actors and increase the quality of work performed by actors in the association. The objectives of the professional association therefore became to represent carbon accountants ("Conseil relatifs aux émissions de Gaz à Effet de Serre" - Consulting on GHG emissions), raise the quality of services, involve members in efforts to professionalize their industry and finally to lead the industry built around consultancy for GHG emissions (creating and steering professional exchanges).

\section{Stepping up quality in professionals}

In 2012, the APCC proposed two standards for qualifying organizations under the French standard-setting organization OPQIBI (Organisme de Qualification des Prestataires d'Ingénierie), which specializes in engineering standards. The latter were drafted by the French environmental protection agency, the APCC and a "Territory and Environment" trade union. The organizational standard was designed to acknowledge the competency 
and professionalism of a design office and to reassure clients on their choice of partners to lead their carbon-related projects (APCC website).

The certification obtained was a certification of "means", which basically attests to the fact that the certified design office already demonstrated its ability to perform carbon accounting, and had the specified means (human and methodological) to continue to perform the standard tasks mentioned. Standard 0605 related to drawing up a Bilan Carbone and an action plan, while standard 0606 related to assistance in carrying out the action plan for reducing GHG emissions. The first offices were qualified in 2013. The ministry wanted the certification to be systematically requested in all specifications.

The APCC also developed networking and exchanges between its members through technical days and regional groups. These initiatives were meant to develop a common culture and the sharing of best practices, and were often co-developed with the EPA.

\section{Counter-work}

\section{Counter-work on knowledge work}

Counter-work: creating a new methodology and "abandoning" the tool created

In 2010, the EPA was mandated to write a methodology for carbon reporting required by Article 75 of the Grenelle 2 Law. In France, national regulations are traditionally based on ISO standards when they exist, therefore the law on carbon accounting refers to ISO standard 14064-1, the mirror of the GHG Protocol, limited to scopes 1 and 2 [3]. The French environmental protection agency therefore wrote a new methodology named "Bilan GES", and no longer recommended the Bilan Carbone as the methodology for the regulation (Bilan Carbone covers all three scopes).

This created confusion in the carbon accounting market. From 2004 to 2010, the Bilan Carbone had been the only tool available for calculating carbon emissions, now suddenly a new and competing methodology had appeared on the market. When looking for carbon accounting services for their organizations, managers had to "choose" between the Bilan GES and the Bilan Carbone. Many were confused, as both had the seal of legitimacy from the French environmental protection agency, so they chose the "cheaper" option, which includes a minimal service covering scopes 1 and 2. The burgeoning profession was puzzled about why the EPA had abandoned the Bilan Carbone tool. Indeed, the agency judged that "it was not worth continuing to maintain a tool that was already mature." (French EPA 4).

Everyone in the emergent professional field condemned this decision, stating that the French environmental protection agency was the only body with the legitimacy to support 
the tool (Bilan Carbone), and that the transfer of the Bilan Carbone (to the ABC, a new association), had caused a lot of damage to the profession (consultant 1 ).

As a result, the financial subsidies for the Bilan Carbone disappeared. By giving up the Bilan Carbone tool to a private association, the value and legitimacy that the Bilan Carbone had acquired through its affiliation with a public institution were lost. When the French environmental protection agency reconsidered its own role in developing competent people and a market, and then abandoning it after determining it to be a mature field that could live on its own, it recalled:

"We have a certain responsibility, both for the successes and failures. (...) We mothered the consultants too much. When I hear some consultants, I get the impression that we washed their brains, they repeat the 'French environmental protection agency mantra' instead of pepping it up. I think we are somewhat responsible for that, no doubt, because we set up a system. There were the pre-technical specifications for the Bilan Carbone, the agency's recommendations on action plans, the tool, etc. This is really the flip side. I think we have a great responsibility in this. It's kind of a love/hate relationship, because we keep tossing the hot potato of failure back and forth." (French EPA 4)

The APCC did not take over the Bilan Carbone tool, although it was at the core of their expertise. The APCC steering committee immediately considered that if the APCC claimed the Bilan Carbone as its own, the association would lose a huge part of its legitimacy. It would become the tool of professionals and consultants selling their wares. It would no longer be credible in the eyes of potential customers. The APCC suggested the creation of the "Association Bilan Carbone (ABC)" to own and continue to develop the tool. Until late 2013 , the APCC had a right of veto at the ABC board level. However, the ABC could become an independent agent now that this right of veto had expired. The future of the Bilan Carbone, which formed the basis of carbon consultants' expertise, was no longer directly linked to the professional association. Both the expertise defined in the tool, and the economic model and strategy of the association could now be modified in a way that could be detrimental to the profession.

Counter-work: Choosing to expand access to carbon accounting expertise rather than developing deepened and exclusive expertise

The French EPA created a training course that was quickly assimilated to an accreditation, when they launched the Bilan Carbone. However, the training course was simple, split into two two-day periods, and people left with a certificate, which confirmed and acknowledged their participation in the course. To obtain the certificate, participants just had to stay nice and quiet for the four days of training (consultant 8). Assimilating it with the accreditation led to a great deal of confusion in the market. After the French EPA 
withdrew from the field, the only way of becoming a carbon accountant remained the two two-day training courses on the Bilan Carbone.

Second, the training centre for carbon accounting was singled out and dissociated from the tool - whereas initially the core expertise was the tool, with the training providing the main access to the tool. The APCC decided to keep carbon accounting training within its own organization, creating the IFC training institute. It wanted to create a professional institute focusing expertise on carbon accounting. Today, the IFC is still the only training institute accredited to run the two two-day training courses on the Bilan Carbone tool. Unfortunately, the IFC's identity diverged from the start from the definition of a "conseil carbone" and the professional tasks associated with it. Before the association's work on their name and core expertise had been completed, the institute had already developed training courses on other environmental topics, including biodiversity management. The "counter-work" performed by the IFC is that it unconsciously threatens its core expertise by expanding beyond carbon, and its core identity by not aligning the training with the identity work conducted by the APCC.

\section{Counter-work on identity work}

\section{Counter-work: competition from other professions}

Carbon consultants had a hard time defending their expertise against other professions. Compliance and certification multinationals, for example, started offering carbon accounting as part of packages sold along with their own activities. Although the carbon accounting consultants claimed to be the only trustworthy "experts", stating that competitors were selling standardized, "accounting-only" deals, there was no regulation and no professional certification to stop these competitors entering the market. The carbon accountants' "defence" was based on claims of expertise. While an essential issue for any emerging group is which other groups accept its claims to legitimacy (Bucher, 1988), the carbon accountants were clearly not accepted by the market as the only possible group able to conduct carbon accounting. Compliance and certification multinationals managed to break the claim made by the APCC members that they were the only legitimate group to perform carbon accounting.

The APCC professionals work in smaller-sized companies as opposed to multinational organizations like the Big Four, who could at any moment redefine the rules by imposing the American standard of carbon accounting (GHG Protocol, predominant worldwide) through the supply chain of the multinationals they work with. The French multinationals that had originally tested the Bilan Carbone in its early days, had already complained that it couldn't be used in their business units outside of France, mainly because of its integrated French database of emission factors. The international de facto standard for carbon accounting is the GHG Protocol Corporate Standard (Green, 2010; Ranganathan, 
2011) and if French multinationals companies decide to follow the crowd, their supply chain and providers could be obliged to follow - leaving the Bilan Carbone on the bench.

On the other hand, the chartered accountancy board director also came to see the APCC so that chartered accountants in France (experts-comptables) could be trained to perform carbon accounting. This probably played a role in the APCC's decision to move away from accounting-only services to wider climate change expertise (consultancy), feeling threatened by the possibility that chartered accountants could offer the accounting service (as they were doing), and destroy the profession:

"Accountants have 'hard' skills that they bring with them into the field of carbon accounting. They enter the field of our expertise through the logic of environmental accounting, but the subject of carbon consultants is not just about accounts. It's accounting that comes to meet carbon, not the other way around." (Consultant 2)

The APCC continued to lobby for expanded regulation, including scope 3 , to try and block the path for other professionals, especially accountants:

"I'm thinking of accountants. If we include scope 3, it'll be harder for them. But the market may be more advantageous, which means that other professionals - energy professionals will develop more in this type of business. LCA [life cycle assessment] specialists may also decide to come into this sector. In other words, there'll always be a lot of people." (Consultant 3)

\section{INSERT FIGURE 4 ABOUT HERE}

A rework of carbon reporting regulations could have supported the expertise developed by carbon accounting professionals, but it could also have paved the way for attacks from other environmental accounting or environmental engineering professionals. The APCC market for carbon accounting and consulting was also under threat from several groups, including the "Big Four" accounting multinationals, other environmental engineers and chartered accountants.

\section{Counter-work on advocacy}

First, the APCC's advocacy was heard but went unheeded. The legitimate interlocutor on carbon accounting topics was still the EPA, even after they had given up on the Bilan Carbone. The APCC did not manage to raise its voice and gain legitimacy with respect to its professional expertise. In appearance, the professional association followed a traditional path as the leading institution for the carbon accounting profession in France, initially acting as a would-be gatekeeper, but over time adopting a more pragmatic stance, 
trying to ensure its "own survival and continued relevance" (Kipping and Kirkpatrick, 2013).

Secondly, powerful actors from within the profession sometimes speak on behalf of the profession (Sikka and Willmott, 1995). For example, the large consultancy firm founded by the creator of the Bilan Carbone, which was not part of the APCC - made the burgeoning profession's advocacy harder to hear. Indeed, the creator of the Bilan Carbone was wellknown and legitimate, and therefore trustworthy (and listened to) in terms of his own discourse on carbon accounting and climate change. Additionally, it meant that different voices (including from the aforementioned large consultancy or from the Big Four) could transmit conflicting messages.

Finally, when the decree on a carbon reporting perimeter (related to the Article 75 Law) was discussed, to see whether it would include scope 3 corresponding to Bilan Carbone accounting, the APCC's voice was silenced by corporate lobbying from French employers' organizations. The consultants from the APCC were pitted against professional lobbyists. Their voice was heard but not listened to. As a consultant pointed out:

"Organizations listen to us but do not hear what we are saying. Something that really annoys me is that when we're on committees with governing bodies or companies, the word of carbon consultancy professionals - i.e. that of the APCC-is not always heard because the other stakeholders feel that we're just profiting from the increasingly restrictive regulations applied to companies and authorities." (Consultant 3)

\section{Absence of work}

\section{Absence of ring-fencing around the knowledge base}

When discussing professionalization projects related to "traditional" professions, one of the key boundary works is to establish control over competencies, their acquisition and maintenance (Weeden, 2002). The APCC "owned" the training on the tool and designed, with the engineering standard-setter, two professional quality standards linked to carbon consultancy. However, the association did not require an entrance examination for entry to the profession. Changing access to the profession would require the joint work of the $\mathrm{ABC}$, which is the sole owner of the methodology. The APCC was not able to develop education beyond the two two-day training sessions through, for example, university programmes that would develop specific expert knowledge (Reed and Anthony, 1992). Monopolizing particular expertise "enables a particular material ordering of the world to the exclusion of alternative ways to 'make sense' of reality" (Hodgson, 2002), but in our case, the professional body of knowledge is scattered among three entities (The EPA, the $\mathrm{ABC}$ and the APCC). 
The EPA had always defended the expansion of carbon accounting knowledge through the Bilan Carbone training courses, and was against the possible control of competencies that would belong to a group of experts - disconnected from a potentially wider network of expertise. The agency purposively avoided ring-fencing as it believed that extensive diffusion of carbon accounting knowledge was serving the French climate change strategy and emissions reduction target.

\section{Absence of global advocacy}

The Bilan Carbone's development was fostered by the French EPA as it was serving the French climate change strategy. It was a national carbon accounting tool for use by French business organizations (and territories) and would help to achieve the French emissions reduction target. Instead of deciding on an expansion strategy outside of French borders, the French EPA concentrated on developing the diffusion of the tool amongst French organizations.

On the other hand, the American standard GHG Protocol, after it was promulgated in 2001, immediately started a strategy of international expansion, working directly with states (Mexico), global organizations such as the CDP and trusting the international standardization of carbon accounting. The ISO 14064 standard, when first promulgated in 2006, was a near exact copy of the GHG Protocol Standard. This reinforced the American carbon accounting standard's hegemonic presence within organizations, notably through multinationals and the Big Four accounting firms.

The French EPA reacted relatively too late to the strategy of the American standard-setter, which was trying to impose its GHG Protocol standard as the de facto world carbon accounting standard. It realized that even the Bilan Carbone might be wiped out in France as large multinationals were already using the GHG Protocol. From 2007, the EPA managed to take over the presidency of the AFNOR commission on climate change. It proposed a group to draft a technical report on ISO 14064, and ultimately wrote a technical report, which describes how to account for scope 3 emissions (which were not initially included in the GHG Protocol Standard from 2001 and 2004, but which were however accounted for in the Bilan Carbone from the start). This technical report provided the framework for ISO 14069, finalized in 2013:

"There was, in particular, the GHG Protocol's desire to dominate. In such circumstances, we had to fight. The GHG Protocol had inspired standard 14064. If we wanted to bring parts of the French methodology into the standard, we had to grasp the opportunity.... We've neglected the international dimension up to now and developed only in France, which is a mistake." (French EPA 1) 
In 2013, the agency obtained the revision of ISO 14064, providing a French secretariat and jointly chairing the working group with a Chinese representative. The role of international standardization (and advocating for the inclusion of the Bilan Carbone's specificities) was finally understood as also serving France's own national interests.

\section{Discussion}

The aim of our paper has been to explore our empirical and theoretical understanding of the birth of a profession in environmental accounting in France. Firstly, we contribute to further characterizing the creative institutional work of change agents in a contemporary professional project. We establish that professionalization projects are the interaction of three types of institutional work: the development of a new expertise as the foundation for new professions, the development of an identity, and the development of soft boundaries that allow expertise and identity to crystallize into forms such as formal training or associations. Secondly, through our findings, we contribute to broadening our knowledge on counter-work and the absence of work, in other words the undermining of professional work by both insiders within the professional carbon accounting field and outsiders through what we name sabotage work.

\section{Creative work}

\section{Knowledge work and boundary work: discussing the network of expertise}

We contribute to an understanding of "knowledge work" and "boundary work" within a professionalization project. Our case study raises questions on a nascent profession's need to ring-fence its expertise - to impose control over it, or on the contrary to build an expertise network (Eyal, 2013). Behind this question on knowledge work, there is also the question of the potential reaction of competing professions - who could access knowledge more easily. The question of knowledge is therefore both a fundamental question as regards the foundation of a new profession, and a fundamental question of "closure" and "control".

In the past, the accounting professionalization literature has drawn extensively on the notion of "closure" and monopoly around a new professional project concept, insisting on the need to exert control over knowledge (eg, Larson, 1977). On the contrary, our research, in line with Matthews (2017), is a case of "non" closure or ring-fencing around the expertise (and the tool) created. Our study emphasizes how a professionalization project where the expertise was constantly extended to a wider network foster the emergence of a profession. 
We therefore analyzed the work related to building a new expertise by looking at how social-material arrangements are constructed to form a network (Eyal, 2013). The main actor of carbon accounting expertise, the French environmental protection agency, considered that the extensive diffusion of carbon accounting expertise was the key to achieving the French climate change strategy. Several key strategies were deployed by the EPA to create the expertise network.

Firstly, the material arrangement for carbon accounting was a "public" accounting tool that was readily available to anyone. It did not become the monopoly of a certain elite, which was the case of the French ecobilan in the '90s (Gibassier, 2017). Secondly, the agency fostered the rapid development of a professional group in terms of practice and market. It created a social arrangement around the tool to diffuse expertise. The carbon profession ensuing from development of the Bilan Carbone tool was a means of meeting these goals because of the privileged relation it could develop with its clients. It became clear to the EPA that the development of the profession was essential for the development of expertise and for achieving their goals. However the agency was more interested in the expertise, i.e. using the profession as a relay for its development, than in the experts themselves (collegial profession model - Walker and Shackleton, 1995). The state agency's original mission included disseminating environmental knowledge but not creating new professions. It made carbon accounting expertise transparent and "standardized". Consequently, the tool was easily understood and applied by professionals, but also by competing professions that enter the market later, such as the conformity and certification organizations or even chartered accountants. By doing so, it might have momentarily weakened the burgeoning profession, but it greatly increased the authority of carbon accounting expertise in France. In new professions, monopoly and autonomy (Walker and Shackleton, 1998) might actually prevent the extension of a network of expertise and may even weaken it (Eyal, 2013).

Finally, the socio-material arrangement around carbon accounting knowledge - the tool and the would-be professionals - has continued to develop, and after 2010 was split into a network of three entities: the EPA, which controls the emissions factor database and the technical discourse on carbon accounting (including participating in international standard-setting); the APCC and its training institute; and the ABC, which actually owns the tool, and which is responsible for developing a system to manage climate change, as well as developing the tool's international dissemination. The network of expertise had considerably extended from the original tool to incorporate more actors and develop extensive technical carbon accounting knowledge in different sectors. As Eyal (2013) demonstrates that a network of expertise is strengthened not by restricting the supply of expertise but by extending it. Co-production, extension and linking make the network more powerful (Eyal, 2013). 


\section{Knowledge work and identity work}

In general, innovations related to accounting are absorbed by the accounting profession at some point (O'Dwyer et al., 2011), whether they have been shaped accountants or not (Armstrong, 1985). For instance, Life Cycle Assessment (LCA), conceived in France by elite engineers, was gradually integrated into the accountancy profession when the two specialized design offices became part of PricewaterhouseCoopers (2000) and Deloitte (2013), and did not lead to the birth of a new "chartered accountancy of the environment", as initially hoped for by the founder of the Ecobilan (Gibassier, 2017).

However, in our study, carbon accounting expertise grew as a separate network. This can be partly explained by the centrality of the Bilan Carbone carbon accounting tool in the professionalization project, and the fact that the tool was public and available for all. The would-be professionals could have owned the tool through the APCC (their professional association), as the measurement tool is at the centre of who they are and what they do. However, they refused to own the tool and decided that a "neutral" external association, the $\mathrm{ABC}$, created to host the tool, would be the best situation, effectively making it available to anyone. Leaving the tool publicly accessible was a risky strategy, as anyone, including the accounting profession or established professional engineer groups, could have competed for the market. At one point in time, the conseil carbone professionals, fearing that the chartered accountants would take carbon accounting into their jurisdiction, even moved their identity from "accountants" to climate change strategists. However, the fact that the tool remained public and open-access (with training as the only barrier), meant that no one could really "own" carbon accounting expertise, with the exception of the initial group of consultants trained from 2004 to 2010. Contrary to "private" tools, such as the LCA developed by the Ecobilan, the Bilan Carbone was never bought out by a profession. Being unsure of whether they would keep their grip on carbon accounting, the would-be professionals moved away from representing themselves as accounting specialists to considering themselves as climate change mitigation specialists. While measure is power (Crosby, 1998; Porter, 1995), keeping their ability to be recognized both as carbon accountants and the providers of mitigation solutions could help to develop their future identity.

\section{Sabotage work}

Counter-work

We introduce the notion of counter-work, which illustrates that the first steps of a nascent profession do not happen in a vacuum where there would be no resistance from actors in the field. The construction of a profession is an interplay between actors with divergent interests and visions. The institutionalization process of a profession is the result of various contradictory or complementary institutional works performed by multiple 
actors (Lawrence et al., 2011). This counter-work - which can be defined as countermining actions that seek to prevent creative work from achieving the full potential of a finalized professionalization project, is conducted with the intent of preventing the nascent profession from stabilizing or fulfilling that project.

First, a nascent profession should have its claims accepted by significant sponsors, allies and other stakeholders (Bucher, 1988). Without a support network, the would-be professionals will have great difficulty developing their creative work. Indeed, even if it successfully disseminates its perspective on the cultural definition of an activity, a new profession is unlikely to persuade relevant audiences to adopt the group's perspective (Nelsen and Barley, 1997) - extra work should be conducted regarding avoiding the counter-work that we observed in the French carbon accounting field. In the case of the French carbon accounting profession, powerful actors in the field, such as Carbone 4 or the Big Four, purposively decided not to adhere to the new APCC association, and therefore constructed a multi-actor arena on carbon accounting. Additionally, they knew that by remaining independent from the APCC, their powerful voices would be listened to, while their presence in the field would silence the APCC's voice.

While the role of competing forces within the carbon accounting professionalization field is a mode of "episodic power" (Lawrence and Buchanan, 2017), the role that the state played through the EPA in the development of this nascent profession is that of a disciplining force that dominated the group of would-be professionals through "systemic power" (Lawrence and Buchanan, 2017). The EPA exercised institutional control over the field through its mastery of the tool, its carbon accounting expertise, and the legitimacy it created for itself as the French centre of expertise on the topic. It lent legitimacy to the tool and reduced uncertainty regarding the new expertise (Lawrence and Buchanan, 2017). Through its work in the early development of the carbon accounting field in France, the state agency disciplined the group of would-be professionals through its shaping of the tool, the training it provided, and the potential customers it encouraged (through financing). In this way, disciplinary practices are a positive form of power as they create identity and motivation for actors (Lawrence and Buchanan, 2017). In 2010, when the EPA decided the accounting tool was mature enough to release from its hold, the whole topic was transferred to the group of new professionals, who were asked to "professionalize" and find a solution for the tool's future development because of the market's dependency on it. Although the agency believed it could easily let the tool go, and allow the consultants to become their own profession, it did not foresee the consequences of releasing its institutional control over the emergent field. The consequences were that neither the APCC nor the ABC were lent the legitimacy of the state agency in embodying carbon accounting expertise alone, and that by not supporting coherent regulation or ring-fencing around the expertise, they were not "freeing" the professionals to build a strong and mature profession, but sentencing them to being 
potentially controlled by others (such as by interventions by more powerful actors including the Big Four). This rupture with the emergent professional field after 2010 had a huge impact on the nascent profession's development. The accounting tool lost the seal of legitimacy granted by the state agency and the legitimate discourse was lost because it was split into three different voices. Finally, the state agency abruptly stopped its financial subsidies for the Bilan Carbone as well as the organizational support that its local delegations were offering to help spread the tool. The professionals felt "let down", the dependency relationship between the agency, the tool and the professionals ran deep they use the word "mothering" - and this abrupt severing had consequences on the fragmentation of the field. It became composed of multiple and relatively uncoordinated sources of authority and influence (D'Aunno et al., 2000). Without legal protection (closure) and using expertise (the Bilan Carbone) no longer directly related to the state, the "mothered" profession was not able to gain any regulatory power in the field.

Moreover, the French environmental protection agency accepted a state mandate to write the carbon accounting methodology linked to the regulation, which defines obligatory carbon reporting. The resulting "Bilan GES" (GHG accounting) confused potential clients into believing that the state agency had dropped the Bilan Carbone tool and written a second, competing carbon accounting methodology, creating a de facto competitor for carbon professionals. By altering the range of options available to actors (Lawrence and Buchanan, 2017), and changing the material technologies available for accounting for carbon, the EPA continued to dominate the field. While the action of creating a competing methodology was intended, the consequences on the burgeoning profession were probably greater than it had anticipated (many design offices closed down and the number of APCC members fell from 100 to 60 when the competing methodology was introduced). The counter-work of the state agency was therefore detrimental to its objective of diffusing expertise on carbon accounting as widely as possible. The creation of the second methodology in fact shrunk the market for the Bilan Carbone. This demonstrates that actors do not necessarily have a sufficient mastery of their institutional work and its consequences, especially in the emergence of a professional project.

\section{Absence of work}

We identified the "absence of work" as a purposive, strategic action. The absence of work is not an omission but an action whose objective is to create an effect. This effect is not produced when the absence is filled, but because of the gap it persistently entails (Giovannoni and Quattrone, 2017). The absence of work is endowed with causal power. However, this type of institutional work intervenes in an open social system where the actions of other actors can interfere with it, which renders the result of this action uncertain (Leca and Naccache, 2006). Other actors might themselves react through counter-work. As observed in the work of Ramirez (2001), this type of institutional work 
appears to be a rare strategy, but is often used by public or state entities, such as the EPA in our case, mainly because it is a risky strategy that requires a position of control and surveillance compared to all other actors in the field.

The APCC decided that it would not ring-fence access to the profession, through an entry examination of knowledge, for example. Unlike the creators of LCA (Gibassier, 2017), who standardized the methodology to the highest quality possible, obliging all potential entrants to the field to conform to their standards, the APCC believed that it would be better to see the profession grow by letting people enter the profession. Its ultimate goal is to combat climate change, and a critical mass of "carbon accountants" is necessary to achieve this role. At the same time, the APCC tried to maintain a certain quality of work, through training and the design office quality certification, as low quality accounting would not contribute to the common good (such as for example when it realized that some large organizations were selling the Bilan Carbone as a loss leader product). To conclude, the work performed by the nascent profession was not always successful, as it requires a high mastery of the field, and because it interacts with other actors present in that field.

The lack of global advocacy for the Bilan Carbone can be attributed to the clear willingness of the French environmental protection agency to develop a tool to support a national climate change strategy. However, the carbon accounting field has been international since the beginning, and both the Bilan Carbone and the GHG Protocol Corporate Standard were conceived at the same time (1998/99 to 2001/2003). The latter has achieved considerable international recognition, while its French counterpart remains limited in its development. Consequently, the organizational professionalization of carbon accounting through the Big Four accountancy organizations (Cooper and Robson, 2006; Kipping and Kirkpatrick, 2013) has been achieved through the dissemination of the GHG Protocol, especially within their French multinational clients. The birth of professions has often been described in national settings, (Ramirez, 2001; Dessalegn et al., 2012) but contemporary professional projects are often subject to international influences on their development (Caramanis, 2002). The global carbon accounting agenda has had a strong, albeit indirect, impact on the development of the French profession. The tool is purely French and has had a hard time being recognized on the international stage. Both the EPA and the $\mathrm{ABC}$ are now trying to make up for lost time through international standardization work at ISO and by disseminating the Bilan Carbone tool in Germany and Mexico (2014). This absence of global advocacy and the non-recognition of the global nature of the carbon accounting field has hindered the initial knowledge work by the EPA, which has been trying, since the early days of the Bilan Carbone, to develop the widest expertise network possible. The backlash from this absence of work is that the expertise network is under attack from a competing global carbon accounting methodology, and the network would have shrunk or disappeared if the agency had not changed its position on global advocacy. 


\section{Conclusion}

This paper analyzes the emergence of an environmental accounting profession built on carbon accounting expertise over the period from 1999 to 2015. Based on participant observation, interviews and the collection of a secondary dataset including archives, it seeks to broaden our understanding of the creative work and sabotage work involved in a professionalization project in a new contemporary empirical setting, namely carbon accounting. Through a rich empirical study of one of the first environmental accounting professions analyzed, it highlights the complexity of a professionalization project anchored in a dynamic field where global and local forces collide and where accounting and engineering logics interact.

Our research has certain limitations. First, the professionalization project under study is a relatively recent phenomenon. One must also acknowledge that the timeframe of the study (16 years), compared to other nascent professions' studies (Edwards et al. 2007, 80 years), makes it difficult to conclude on whether the nascent profession will develop, or disappear. Second, we were not able to attend insider meetings of the professional association, although one of the researchers approached regional representatives for access. This would have granted us an even closer look into the malaise and discussions around the professionalization of carbon consultancy in France.

Finally, we contributed to the environmental accounting literature by adding to the very first accounts of how professional projects can emerge in this field (Power, 1997; O'Dwyer et al., 2011; Malsch, 2013; Renaud, 2014). Further research should be conducted to investigate the link between environmental accounting innovations and professions. Armstrong (1985), for example, first showed how accountants took over standard accounting from engineers. Accounting innovations can be at the centre of professional disputes, at the birth of new professions, or can be actors in the deinstitutionalization of professional projects. Moreover, the carbon accounting field can now be considered international with several hot spots in the USA and Australia, where other professionalization projects could be researched and compared. The role of the accounting profession in absorbing environmental accounting tools and practices could be further analyzed through its rhetorical institutional work (Suddaby et al., 2015), such as writing reports, books and articles in professional journals, its boundary work, such as by integrating knowledge into examinations (e.g. ACCA with integrated reporting) and finally its counter-work (lobbying and "non-aggression" treaties, e.g. Humphrey et al., 2015). The difference in strategies in relation to environmental accounting by professional associations versus professional service firms (the Big Four) must be carefully analyzed (Power, 1997; O'Dwyer et al., 2011; Malsch, 2013). The accounting profession's ambiguous relationship with environmental accounting in the last 40 years has had a considerable impact on the development of environmental accounting tools and 
practices by other groups, including engineering professions and global organizations such as the big accountancy firms that regularly absorb successful environmental accounting and reporting design offices (in France for example, the Ecobilan in 2000 and Bio Intelligence Services in 2013, or the Institut RSE in 2015). Finally, environmental accounting could be professionalized directly within organizations, as the exploratory research by Renaud (2014) investigates in a French organization. Environmental accounting jobs, such as "sustainability CFOs" or "Chief Value Officers" (King and Atkins, 2016) are mushrooming within multinationals and could drive the accounting profession to rethink its relationship with certain environmental accounting practices that have developed outside its own professional field.

\section{Notes}

[1] A design office is an organization in which engineers have the expertise to account for and interpret data, and then devise action plans. Design office is the most common translation that we found but we also found "engineering consultancy" or "technical office".

[2] The number of Bilan Carbones performed in 2010 was 1690 and in 2011, only 750, 650 in 2012.

[3] Scope 1 emissions are direct GHG emissions that occur from sources owned or controlled by the company; scope 2 emissions are GHG emissions generated by purchased electricity consumed by the company; scope 3 emissions are all other indirect GHG emissions - GHG Protocol (2004).

[4] Carbone 4 website: http://www.carbone4.com/fr/l actu de carbone 4/du-bilancarbone-en-2001-\%C3\%A0-1\%E2\%80\%99iso-en-2013 


\section{References}

Abbott, A.D. (1988), The system of professions: An essay on the division of expert labor, University of Chicago Press, Chicago.

ABC (2015), Modèle de licence d'utilisation.

Armstrong, P. (1985), "Changing management control strategies: the role of competition between accountancy and other organisational professions", Accounting, Organizations and Society, Vol. 10 No. 2, pp. 129-148.

Ballas, A.A. (1998), "The creation of the auditing profession in Greece", Accounting, Organizations and Society, Vol. 23 No. 8, pp. 715-736.

Beaverstock, J.V., Faulconbridge, J.R. and Hall, S.J.E. (2010), "Professionalization, legitimization and the creation of executive search markets in Europe", Journal of Economic Geography, Vol. 10 No. 6, pp. 825-843.

Bucher, R. (1988), "On the Natural History of Health Care Occupations", Work and Occupations, Vol. 15 No. 2, pp. 131-147.

Caramanis, C.V. (2002), "The interplay between professional groups, the state and supranational agents: Pax Americana in the age of 'globalisation'”, Accounting, Organizations and Society, Vol. 27 4-5, pp. 379-408.

Carnegie, Garry D., and Edwards, J.R. (2001), "The construction of the professional accountant: the case of the Incorporated Institute of Accountants, Victoria (1886)", Accounting, Organizations and Society, Vol. 26 No. 4-5, pp. 301-325.

Carter, C., Spence, C. and Muzio, D. (2015), "Scoping an agenda for future research into the professions", Accounting, Auditing \& Accountability Journal, Vol. 28 No. 8, pp. 11981216.

Cooper, D.J. and Robson, K. (2006), "Accounting, professions and regulation: Locating the sites of professionalization", Accounting, Organizations and Society, Vol. 31 No. 4-5, pp. 415-444.

Coronella, S., Sargiacomo, M. and Walker, S.P. (2015), "Unification and Dual Closure in the Italian Accountancy Profession, 1861-1906”, European Accounting Review, Vol. 24 No. 1, pp. 167-197.

Creed, W. E. D., Scully, M. A., and Austin, J. R. (2002), “Clothes make the person? The tailoring of legitimating accounts and the social construction of identity", Organization Science, Vol.13, pp. 475-496.

Creed, W.E.D., DeJordy, R. and Lok, J. (2010), "Being the Change: Resolving Institutional Contradiction through Identity Work", Academy of Management Journal, Vol. 53 No. 6, pp. 1336-1364.

Crosby, A.W. (1998), The measure of reality: Quantification and Western society, 12501600, Cambridge University Press, Cambridge. 
Cross, R.L., Yan, A. and Louis, M.R. (2000), "Boundary Activities in 'Boundaryless' Organizations: A Case Study of a Transformation to a Team-Based Structure", Human Relations, Vol. 53 No. 6, pp. 841-868.

D'Aunno, T., Succi, M. and Alexander, J.A. (2000), "The Role of Institutional and Market Forces in Divergent Organizational Change", Administrative Science Quarterly, Vol. 45 No. 4, p. 679.

De Beelde, I. (2002), "Creating a profession 'out of nothing'? The case of the Belgian auditing profession", Accounting, Organizations and Society, Vol. 27, pp. 447-470.

de Sousa Santos, B. (2006), The rise of the global left: The World Social Forum and beyond, Zed Books, London.

Dessalegn, G.M., Kieran, J. and Mula, J.M. (2012), "Accounting professionalization amidst alternating state ideology in Ethiopia", Accounting, Auditing \& Accountability Journal, Vol. 25 No. 7, pp. 1206-1233.

Edwards, J.R., Anderson, M. and Chandler, R.A. (2007), "Claiming a jurisdiction for the "Public Accountant" in England prior to organisational fusion", Accounting, Organizations and Society, Vol. 32 1-2, pp. 61-100.

El Omari, S. and Khlif, W. (2014), "The professionalization of chartered accountants. A comparative analysis of Morocco and Tunisia", Comptabilité - Contrôle - Audit, Vol. 20 No. 1, p. 67.

El Omari, S., Rossignol, J.-L. and Saboly, M. (2013), "The search for unity in the French accountancy profession, 1969-1996", Accounting History Review, Vol. 23 No. 1, pp. 85105.

Etzion, D. and Ferraro, F. (2010), "The Role of Analogy in the Institutionalization of Sustainability Reporting", Organization Science, Vol. 21 No. 5, pp. 1092-1107.

Evetts, J. (2011), "A new professionalism? Challenges and opportunities", Current Sociology, Vol. 59 No. 4, pp. 406-422.

Eyal, G. (2013), "For a Sociology of Expertise: The Social Origins of the Autism Epidemic 1", American Journal of Sociology, Vol. 118 No. 4, pp. 863-907.

Fayard, A.-L., Stigliani, I. and Bechky, B.A. (2017), "How Nascent Occupations Construct a Mandate: The Case of Service Designers Ethos", Administrative Science Quarterly, Vol. 62 No. 2, pp. 270-303.

Gendron, Y. and Barrett, M. (2004), "Professionalization in Action: Accountants' Attempt at Building a Network of Support for the WebTrust Seal of Assurance", Contemporary Accounting Research, Vol. 21 No. 3, pp. 563-602.

Gendron, Y., Cooper, D.J. and Townley, B. (2007), "The construction of auditing expertise in measuring government performance", Accounting, Organizations and Society, Vol. 32 1-2, pp. 101-129.

Gibassier, D. (2017), "From écobilan to LCA: the elite's institutional work in the creation of an environmental management accounting tool", Critical Perspectives on Accounting, Vol. 42, pp. 36-58. 
Giovannoni, E. and Quattrone, P. (2017), "The Materiality of Absence: Organizing and the case of the incomplete cathedral", Organization Studies, Vol. 8.

Green, J.F. (2010), "Private Standards in the Climate Regime: The Greenhouse Gas Protocol", Business and Politics, Vol. 12 No. 3, pp. 1-39.

Groß, C. and Kieser, A. (2006), "Are Consultants Moving Towards Professionalization?", Research in the Sociology of Organizations, Vol. 24, pp. 69-100.

Hampel, C.E., Lawrence, T.B. and Tracey, P. (2017), "Institutional Work: Taking Stock and Making It Matter”, in Greenwood, R., Oliver, C., Lawrence, T.B. and Meyer, R.E. (Eds.), The Sage Handbook of organizational institutionalism, 2nd ed., SAGE Publications Ltd, London, pp. 558-590.

Hayne, C. and Free, C. (2014), "Hybridized professional groups and institutional work: COSO and the rise of enterprise risk management", Accounting, Organizations and Society, Vol. 39 No. 5, pp. 309-330.

Hodgson, D. (2002), "Disciplining the professional: the case of project management", Journal of Management Studies, Vol. 39 No. 6, pp. 803-821.

Hodgson, D., Paton, S. and Muzio, D. (2015), "Something Old, Something New?: Competing Logics and the Hybrid Nature of New Corporate Professions", British Journal of Management, Vol. 26 No. 4, pp. 745-759.

Howard-Grenville, J., Nelson, A.J., Earle, A.G., Haack, J.A. and Young, D.M. (2017), “"If Chemists Don't Do It, Who Is Going To?" Peer-driven Occupational Change and the Emergence of Green Chemistry", Administrative Science Quarterly, Vol. 62 No. 3, pp. 524-560.

Humphrey, C., O'Dwyer, B. and Unerman, J. (2015), “The rise of integrated reporting: understanding attempts to institutionalize a new corporate reporting framework".

King, M. and Atkins, J. (2016) The Chief Value Officer - Accountants Can Save the Planet. Greenleaf Publishing.

Kipping, M. and Kirkpatrick, I. (2013), "Alternative Pathways of Change in Professional Services Firms: The Case of Management Consulting”, Journal of Management Studies, Vol. 50 No. 5, pp. 777-807.

Larson, M.S. (1990), "In the matter of experts and professionals, or how impossible it is to leave nothing unsaid", in Burrage, M. and Torstendahl, R. (Eds.), The Formation of professions: Knowledge, state and strategy, SCASSS, Sage, London.

Larson, M.S. (1977), The rise of professionalism: Monopolies of competence and sheltered markets, University of California Press.

Lawrence, T.B. (2004), "Rituals and Resistance: Membership Dynamics in Professional Fields", Human Relations, Vol. 57 No. 2, pp. 115-143.

Lawrence, T.B. and Suddaby, R. (2006), "Institutions and Institutional Work", in Clegg, S., Hardy, C., Lawrence, T.B. and Nord, W.R. (Eds.), Handbook of organization studies, 2nd Edition, Sage. 
Lawrence, T.B. and Buchanan, S. (2017), "Power, institutions and organizations", in Greenwood, R., Oliver, C., Lawrence, T.B. and Meyer, R.E. (Eds.), The Sage Handbook of organizational institutionalism, 2nd ed., SAGE Publications Ltd, London, pp. 477-506.

Lawrence, T.B., Suddaby, R. and Leca, B. (Eds.) (2009), Institutional work: Actors and agency in institutional studies of organization, Cambridge University Press, Cambridge.

Lawrence, T.B., Suddaby, R. and Leca, B. (2011), "Institutional Work: Refocusing Institutional Studies of Organization", Journal of Management Inquiry, Vol. 20 No. 1, pp. 52-58.

Leca, B. and Naccache, P. (2006), "A Critical Realist Approach To Institutional Entrepreneurship", Organization, Vol. 13 No. 5, pp. 627-651.

Light, D.W. (1995), "Countervailing Powers: A Framework for Professions in Transition", in Johnson, T., Larkin, G. and Saks, M. (Eds.), Health Professions and the State in Europe, Routledge, London, pp. 25-41.

Light, D.W. (2014), "Countervailing Powers”, in Cockerham, W.C., Dingwall, R. and Quah, S.R. (Eds.), The Wiley Blackwell encyclopedia of health, illness, behavior, and society, Wiley Blackwell encyclopedias in social science, Wiley-Blackwell, Chichester, New York.

Lounsbury, M. (2001), "Institutional Sources of Practice Variation: Staffing College and University Recycling Programs", Administrative Science Quarterly, Vol. 46 No. 1, p. 29.

Malhotra, N. and Morris, T. (2009), "Heterogeneity in Professional Service Firms", Journal of Management Studies, Vol. 46 No. 6, pp. 895-922.

Malsch, B. (2013), "Politicizing the expertise of the accounting industry in the realm of corporate social responsibility", Accounting, Organizations and Society, Vol. 38 No. 2, pp. $149-168$.

Matthews, D.R. (2017), "Accountants and the professional project", Accounting, Auditing \& Accountability Journal, Vol. 30 No. 2, pp. 306-327.

McCann, L., Granter, E., Hyde, P. and Hassard, J. (2013), "Still Blue-Collar after all these Years? An Ethnography of the Professionalization of Emergency Ambulance Work", Journal of Management Studies, Vol. 50 No. 5, pp. 750-776.

McMurray, R. (2011), "The struggle to professionalize: An ethnographic account of the occupational position of Advanced Nurse Practitioners", Human Relations, Vol. 64 No. 6, pp. 801-822.

Muzio, D., Brock, D.M. and Suddaby, R. (2013), "Professions and Institutional Change: Towards an Institutionalist Sociology of the Professions", Journal of Management Studies, Vol. 50 No. 5, pp. 699-721.

Nelsen, B.J. and Barley, S.R. (1997), "For Love or Money? Commodification and the Construction of an Occupational Mandate", Administrative Science Quarterly, Vol. 42 No. 4, p. 619.

Oakes, L.S., Townley, B. and Cooper, D.J. (1998), "Business planning as pedagogy: language and control in a changing institutional field", Administrative Science Quarterly, Vol. 43 No. 2, pp. 257-292. 
O'Dwyer, B., Owen, D.L. and Unerman, J. (2011), "Seeking legitimacy for new assurance forms: The case of assurance on sustainability reporting", Accounting, Organizations and Society, Vol. 36 No. 1, pp. 31-52.

Power, M. (1997), The audit society: Rituals of verification, Oxford University Press, Oxford, England.

Porter, T.M. (1995), Trust in numbers: The pursuit of objectivity in science and public life, Princeton University Press, Princeton, N.J.

Ramirez, C. (2001), "Understanding social closure in its cultural context: accounting practitioners in France (1920-1939)", Accounting, Organizations and Society, Vol. 26 4/5, pp. 391-418.

Ramirez, C. (2013), "We are being Pilloried for Something, We Did Not Even Know We Had Done Wrong!' Quality Control and Orders of Worth in the British Audit Profession", Journal of Management Studies, Vol. 50 No. 5, pp. 845-869.

Ranganathan, J. (2011), "GHG protocol: The gold standard for accounting for greenhouse gas emissions”, WRI Insights, 4 October (accessed October, 19th, 2011).

Rao, H., Monin, P. and Durand, R. (2003), "Institutional Change in Toque Ville: Nouvelle Cuisine as an Identity Movement in French Gastronomy", American Journal of Sociology, Vol. 108 No. 4, pp. 795-843.

Reed, M. and Anthony, P. (1992), "Professionalizing management and managing professionalization British management in the 1980s", Journal of Management Studies, Vol. 29 No. 5, pp. 591-613.

Renaud, A. (2014), "The controller's role in environmental management control", Comptabilité - Contrôle - Audit, Vol. 20 No. 2, p. 67.

Richardson, A.J. (1997), "Social closure in dynamic markets: the incomplete professional project in accountancy", Critical Perspectives on Accounting, Vol. 8 No. 6, pp. 635-653.

Selznick, P. (1957), Leadership in administration: A sociological interpretation, University of California Press, Berkeley, Calif.

Sian, S. (2006), "Inclusion, exclusion and control: The case of the Kenyan accounting professionalisation project", Accounting, Organizations and Society, Vol. 31 No. 3, pp. 295-322.

Sikka, P. and Willmott, H. (1995), "The power of "independence": defending and extending the jurisdiction of accounting in the United Kingdom", Accounting, Organizations and Society, Vol. 20 No. 6, pp. 547-581.

Suddaby, R., Saxton, G.D. and Gunz, S. (2015), "Twittering change: The institutional work of domain change in accounting expertise", Accounting, Organizations and Society, Vol. 45 , pp. 52-68.

Suddaby, R. and Viale, T. (2011), "Professionals and field-level change: Institutional work and the professional project", Current Sociology, Vol. 59 No. 4, pp. 423-442.

Van Maanen, J. and Barley, S.R. (1984), "Occupational communities: Culture and control in organizations", in Staw, B.M. and Cummings, L.L. (Eds.), Research in organizational 
behaviour: An annual series of analytical essays and critical reviews, JAI Press, Greenwich, Conn.

Walker, S.P. (1988), The Society of Accountants in Edinburgh, 1854-1914. A Study of Recruitment to a New Profession, Garland Publishing Inc, New York.

Walker, S.P. (1991), "The defence of professional monopoly: Scottish chartered accountants and "satellites in the accountancy firmament" 1854-1914", Accounting, Organizations and Society, Vol. 16 No. 3, pp. 257-283.

Walker, S.P. (2004), "The genesis of professional organisation in English accountancy", Accounting, Organizations and Society, Vol. 29 No. 2, pp. 127-156.

Walker, S.P. and Shackleton, K. (1995), "Corporatism and structural change in the British accountancy profession, 1930-1957", Accounting, Organizations and Society, Vol. 20 No. 6, pp. 467-503.

Walker, S.P. and Shackleton, K. (1998), "A ring fence for the profession: advancing the closure of British accountancy 1957-1970", Accounting, Auditing \& Accountability Journal, Vol. 11 No. 1, pp. 34-71.

Weeden, K.A. (2002), "Why Do Some Occupations Pay More than Others? Social Closure and Earnings Inequality in the United States", American Journal of Sociology, Vol. 108 No. 1, pp. 55-101. 


\section{Tables}

Table 1 The institutional context related to carbon accounting

\begin{tabular}{|l|l|}
\hline Date & Events \\
\hline 1997 & Kyoto Protocol \\
\hline 1998 & GHG Protocol was formed \\
\hline 1999 & Creation of Bilan Carbone \\
\hline 2001 & $\begin{array}{l}\text { GHG Protocol Corporate Standard } \\
\text { launched }\end{array}$ \\
\hline 2004 & $\begin{array}{l}\text { Launch of Bilan Carbone } \\
\text { Revision of Corporate Standard }\end{array}$ \\
\hline $2007-20099$ & Grenelle discussions \\
\hline 2009 & $\begin{array}{l}\text { Havard (French MP) report on carbon } \\
\text { reporting }\end{array}$ \\
\hline 2010 & Creation of APCC \\
\hline 2010 & Promulgation of Grenelle 2 law \\
\hline 2010 & $\begin{array}{l}\text { Decision to separate Bilan Carbone from } \\
\text { the French environmental agency }\end{array}$ \\
\hline 2011 & Creation of Association Bilan Carbone \\
\hline 2011 & Decree related to Art. 75 of Grenelle 2 law \\
\hline 2012 & First mandatory carbon reporting year \\
\hline 2014 & Energetic Transition talks \\
\hline 2015 & France hosts COP talks on climate change \\
\hline
\end{tabular}

Table 2 Progression of Bilan Carbone in France (origin of the data: ADEME and ABC)

\begin{tabular}{|l|l|l|l|l|l|l|l|l|l|}
\hline Year & 2004 & 2005 & 2006 & 2007 & 2008 & 2009 & 2010 & 2011 & TOTAL \\
\hline $\begin{array}{l}\text { Number of } \\
\text { Bilan } \\
\begin{array}{l}\text { Carbone for } \\
\text { companies } \\
\text { only }\end{array}\end{array}$ & 78 & 160 & 160 & 199 & 100 & 1600 & 1690 & 750 & 3713 \\
\hline
\end{tabular}




\section{Figures}

Figure 1: analytical codes

Knowledge work

Identity work

Soft boundary work

Counter work on knowledge work

Counter work on identity work<smiles>CCCCCC</smiles>

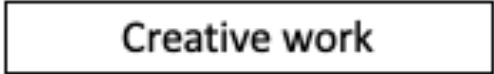

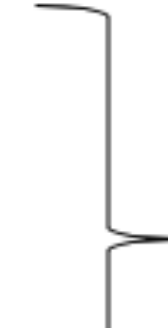
Sabotage work

Absence of work 
Figure 2: The institutional work to sustain the professional project of the "carbon accounting profession"

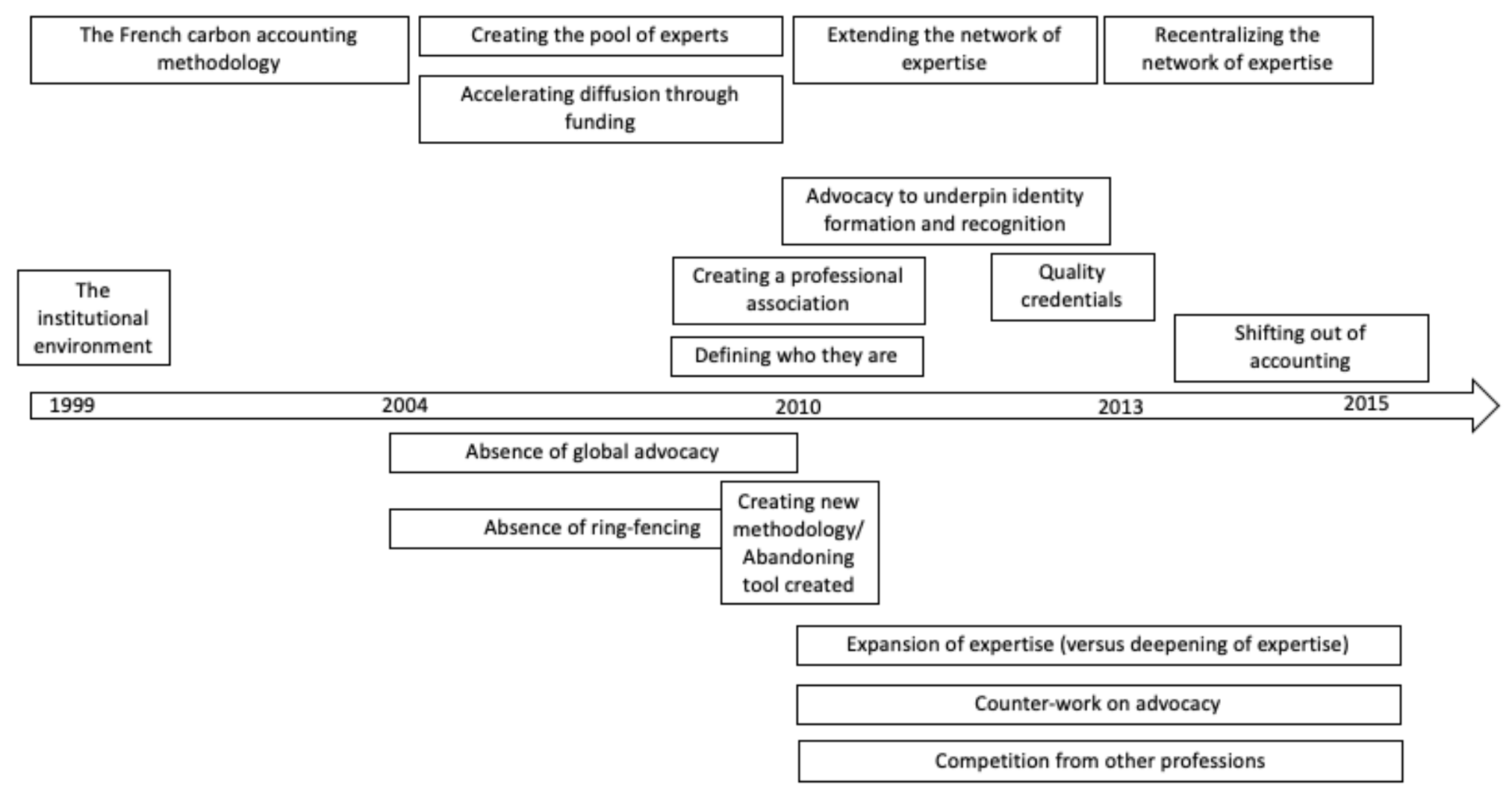


Figure 3: The network of carbon accounting expertise from 1999 to 2015

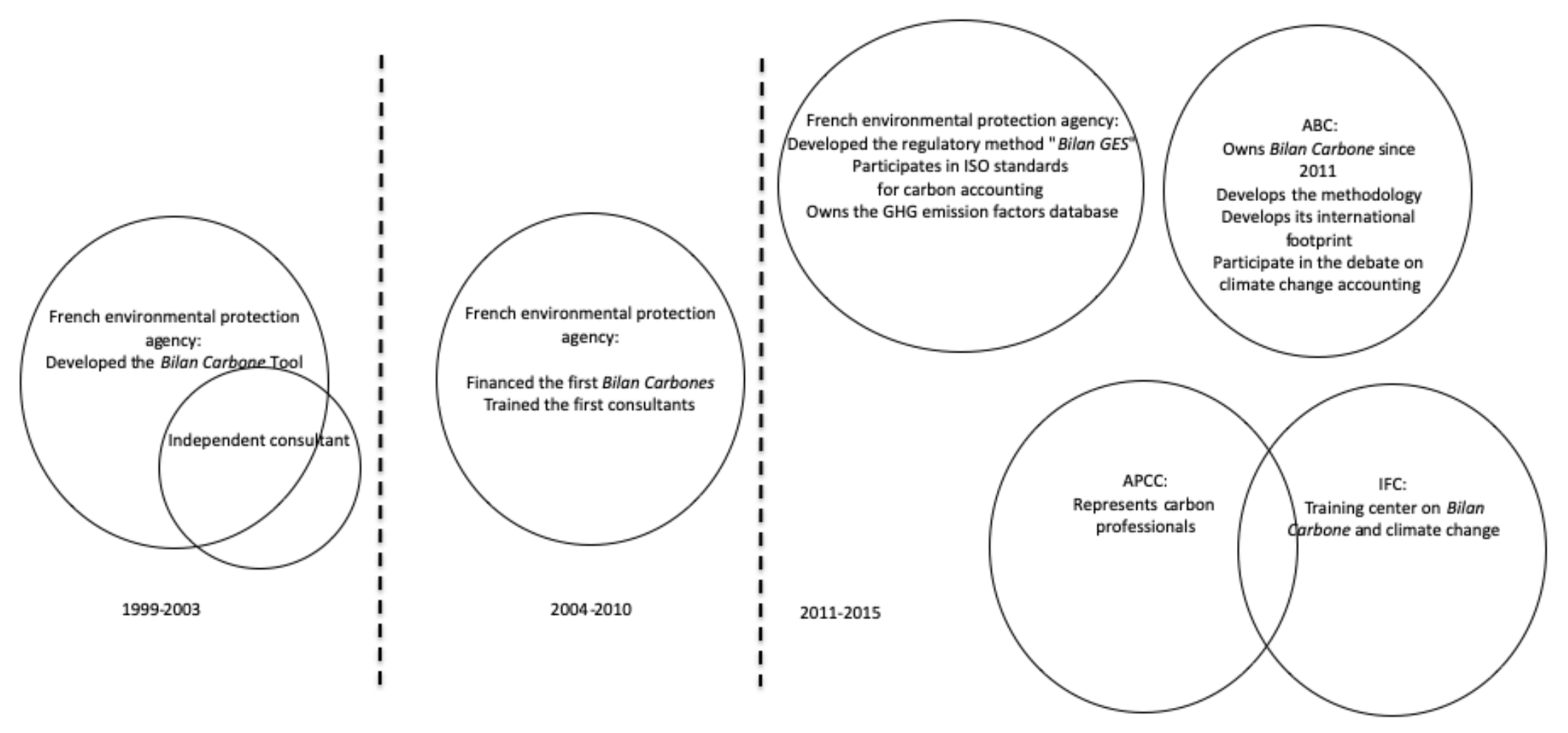


Figure 4: Counter-work around the birth of the carbon accounting profession

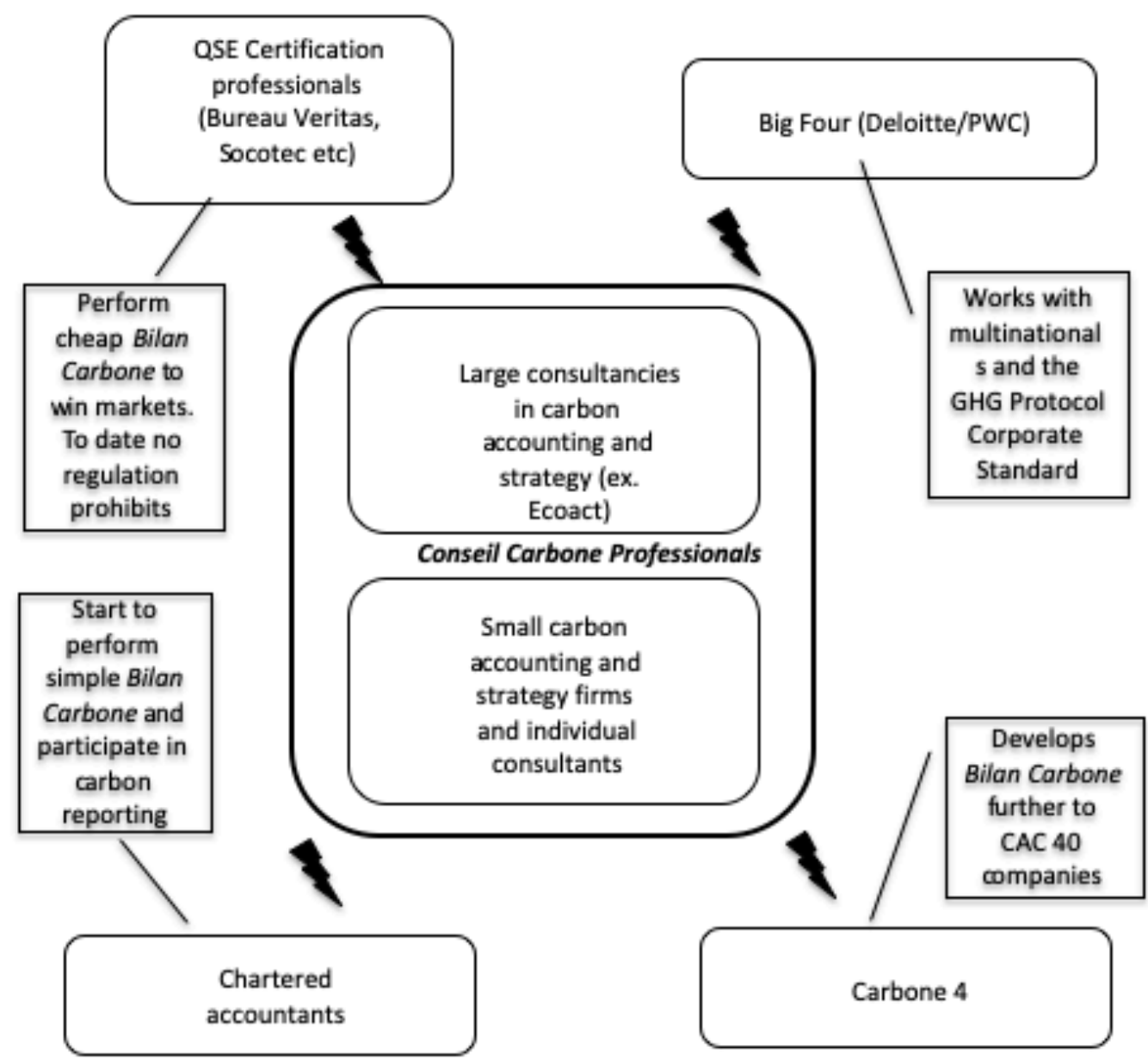

